\title{
RESEARCH OF REMOTELY PILOTED VEHICLES FOR CARGO TRANSPORTATION
}

\author{
Ugnius RAGAUSKAS ${ }^{1}$, Domantas BRUČAS ${ }^{2}$, \\ Jüratė SUŽIEDELYTE் VISOCKIENE் $\dot{E}^{3}$
}

${ }^{1}$ Department of Aviation Mechanics, ${ }^{2}$ Antanas Gustaitis' Aviation Institute Vilnius, Lithuania

${ }^{2}$ Space Science And Technology Institute, Vilnius, Lithuania

${ }^{3}$ Faculty of Environment Engineering, Department of Geodesy and Cadastre,

Vilnius Gediminas Technical University, Vilnius, Lithuania

E-mails: ${ }^{1}$ ugnius.ragauskas@vgtu.lt (correspondingauthor); ${ }^{2}$ dobr@kmti.lt;

3jurate.visockiene@vgtu.lt

Received 03 November 2014; accepted 29 February 2016

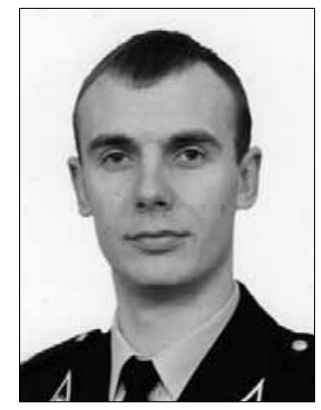

\section{Ugnius RAGAUSKAS}

Date and place of birth: 1989, Šiaulenai.

Education: 2013 Master of Transport Engineering, Antanas Gustaitis Aviation Institute, Vilnius Gediminas Technical University.

Affiliations and functions: PhD student at Vilnius Gediminas Technical University Faculty of Transport Engineering.

Research interests: unmanned aerial vehicles, cargo transportation.

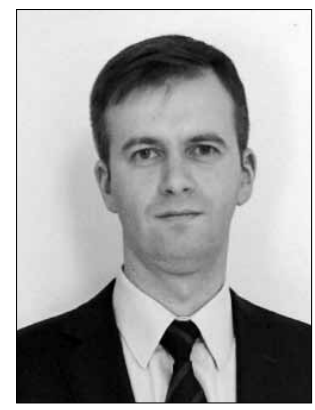

\section{Domantas BRUČAS}

Date and place of birth: 1979, Vilnius.

Education: 2002 Bachelor of Mechanical Engineering, 2004 Master of Transport

Engineering, 2008 Doctor of Measurement Engineering, Vilnius Gediminas Technical University.

Present position: Associated Professor at Vilnius Gediminas Technical University/Director of Space Science and Technology Institute.

Research interest: unmanned aerial vehicles, measurement engineering.

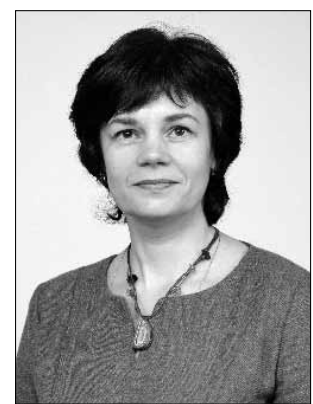

\section{Jūratė SUŽIEDELYTÉ VISOCKIENÉ}

Date and place of birth: 1971, Vilnius.

Education: Vilnius Gediminas Technical University.

Affiliations and functions: Assoc. prof. dr. Head of Department Geodesy and Cadastre.

Research interests: Photogrammetry, $3 D$ object modelling, RPV.

Abstract. Remotely piloted vehicles (RPV) are used in various fields. The article analyses RPV usage for aerial cargo transportation. The first part is an overview of RPVs used across the world as cargo transportation, their examples and prototypes, as well as the comparison of their advantages and disadvantages. The second part is an analysis of aircraft structural components, by comparing their various configurations. The best cargo delivery method is analysed; and a mathematical model of cargo drop from vehicle is presented.

Keywords: RPV, cargo, transportation, delivery methods. 


\section{Introduction}

Remotely piloted vehicles (RPV) can accomplish lot of different tasks. The main task of a piloted aircraft is transporting cargo. RPVs can transport cargo as well. The term cargo includes medical equipment, survival equipment or kits, food (Jones 2007). RPVs can deliver goods very expeditiously (Frew, Brown 2008). To be on time the whole system of an RPV is needed. The main parts of an RPV are, see Figure 1 (Davis 2010):

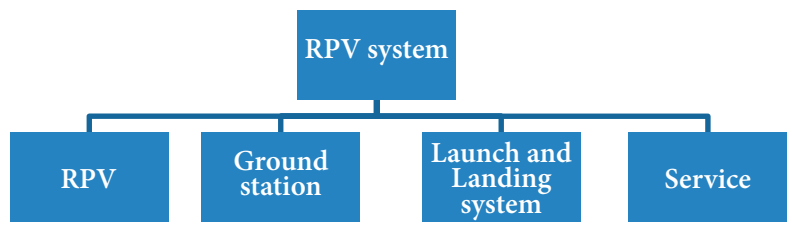

Fig. 1. Parts of an RPV system

$R P V$. There are different types and shapes of RPVs. The most commonly used one across the world is the multi-copter, with good manoeuvrability as well as a vertical take-off and landing. However, its main disadvantage is time in the air.

The Ground station consists of control equipment and an antenna. The antenna may be of different size according to the distance of the operation. It can be both non-directional and directional. Often there is a group of antennas in the operating region. Eric Frew overview of networks provides a number of options for possible telemetry links (Fig. 2) (Frew, Brown 2008). The control equipment depends on the aircraft, so it can vary.

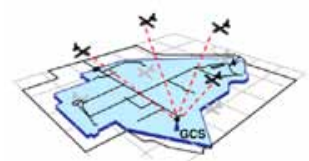

(a) Direct

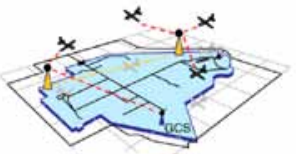

(c) Cellular

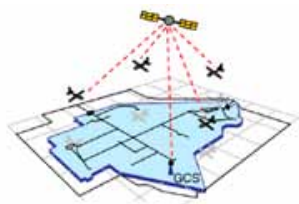

(b) Satellite

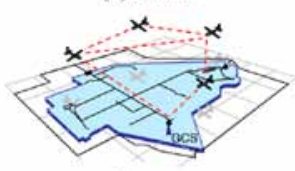

(d) Mesh
Fig. 2. RPV's types of telemetry (Frew, Brown 2008)

Launch and landing system. This system has a number of alternatives. Sometimes the launch and landing system has a sole RPV mounted on the vehicle, but not always. The main launch and landing systems and techniques are presented in Table 1:

Table 1. Launch and landing methods

\begin{tabular}{ll}
\hline \multicolumn{1}{c}{ Launch } & \multicolumn{1}{c}{ Landing } \\
\hline Hand-launched & Catching network \\
\hline Carrier platforms (missiles and other aircraft) & Parachute \\
\hline Catapult & Landing gear \\
\hline Gear & Belly landing \\
\hline Chassis & Vertical landing \\
\hline
\end{tabular}

Service. The aircraft is piloted remotely, sometimes by autopilot. After the flight, the aircraft must be inspected, the parachute packed, required parts replaced, and batteries recharged. Also, the cargo has to be loaded or attached with special equipment.

\section{Overview}

There are currently a number of companies which are engaged in the development of RPVs. Many modern companies such as the giants Amazon or Google operate in many different fields. Also, there are some prototypes by companies; they are not widely used since many of them have just had a few test flights; nevertheless, they have very high potential.

\subsection{AMAZON}

Amazon's CEO has announced the development of a multicopter unmanned vehicle of the miniature UAV class. The aircraft uses a GPS to fly autonomously and deliver the goods to the client within 30 minutes. It is also capable of lifting more than $86 \%$ of Amazon's goods which are transported in an allocated box. However, the aircraft should not be more than 16 miles from the goods. The aircraft development process has encountered a number of problems. Firstly, it is the legalization of the flight. Amazon Prime Air (Fig. 3) cannot be used in the USA for commercial purposes. In 2012, the Congress issued a release stating that the Federal Aviation Administration should prepare the "Integration of civil unmanned aircraft systems into the national airspace system project" by September 2015. This project should help integrate RPVs into the airspace, but it is currently prohibited. Also, Amazon Prime Air can only cover a short distance. Therefore, to service the whole city a huge infrastructure is needed.

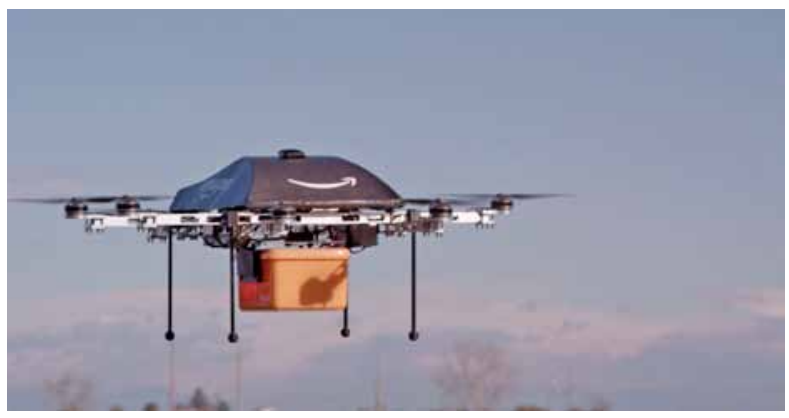

Fig. 3. Amazon prime air (http://www.amazon.com/b?node= 8037720011)

\subsection{Burrito Bomber}

Darwin Aerospace's Burrito Bomber has introduced a small, remotely controlled airplane that drops parachute-equipped burritos to the waiting hands and mouths of customers ordering them by smartphone. Darwin Aerospace is a small research lab. This goods delivering method is quite cheap as it uses well known 


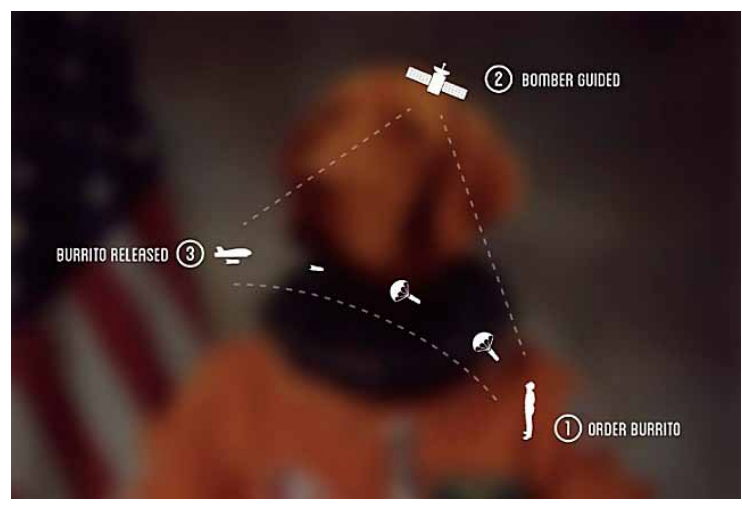

Fig. 4. Principle scheme of the "Burrito bomber" (Source: http://www.darwinaerospace.com/burritobomber)

parts. The airframe is a Sky Walker X8 Flying Wing. The plane also uses the Ardupilot to navigate the skies. The Burrito release mechanism is a combination of a Quantum RTR Bomb System, a 3 inch diameter mailing tube, and some $3 \mathrm{D}$ printed parts that were designed inhouse. The plane is controllable either manually or via a live video transmitted from the plane or autonomously using the Ardupilot autopilot. A Futaba 9C controller and $\mathrm{Ez}$ UHF transmitter are used to manually control the plane, illustrated in Figure 4.

They have also encountered legalization problems. As well as Amazon's drone, it cannot deliver goods in the USA. Some promises have been given that it might become legal in 2015.

\subsection{UAE drone}

The UAE drone (United Arab Emirates) authorities have announced about the development of a drone for delivering goods. They say that aerial drones could be used to deliver vital documents and medicine within a year. A competition has been announced with a prize of 1 million dollars for the best drone for the UAE Government Services. Dr Raford said battery-operated drones, which could cost as little as Dh4,000, could fly up to three kilometres at $40 \mathrm{kph}$ and carry objects weighing up to $1.5 \mathrm{~kg}$, as seen in Figure 5 .

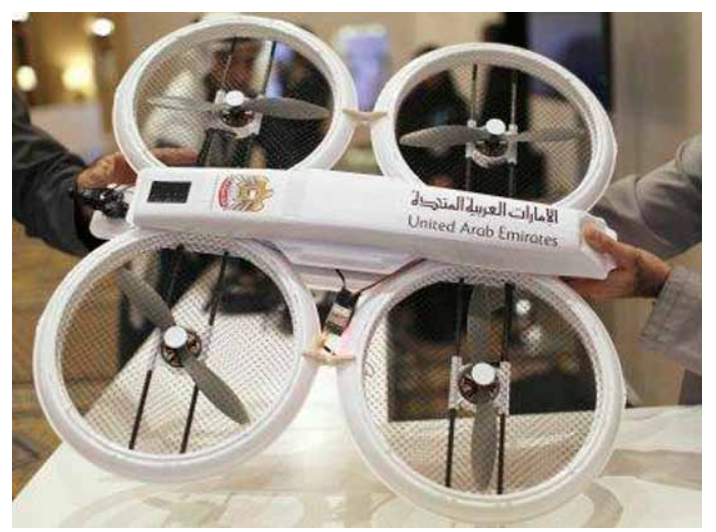

Fig. 5. The UAE drone prototype (Source: http://www. technocrazed.com/uae-government-planning-to-use-dronesfor-delivering-official-documents)

\subsection{Google $\mathrm{X}$ wing project}

The deliveries in this project were made by a $1.5 \mathrm{~m}$-wide (5 $\mathrm{ft})$ single-wing drone prototype that has four propellers that move into different positions for different stages of flight. The packages are fitted into a gap in the middle of the wing. This is a hybrid of a plane and a helicopter that takes off vertically, and then rotates to a horizontal position for flying around. For the delivery, it hovers and a winch lowers the packages down to the ground. Google has considered several methods of actually delivering the package, including one by parachute (like in The Hunger Games), as well as landing the drone. The latter has proved to be problematic with Google fearing that people might risk injury by getting too close to the drone's rotors while fetching their delivery. Google has also carried out an experiment in which a type of fishing line was used to lower the payload to customers from about 150 feet above the ground, illustrated in

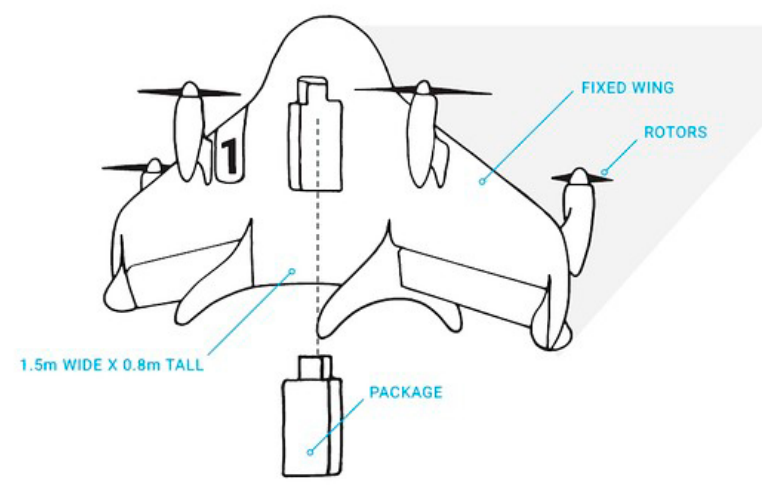

Fig. 6. Google X wing vehicle (Source: http://thehigherlearning com/2014/09/01/secret-google-X-project-bringing-us-a-stepcloser-to-drone-deliveries-video/)

\section{RPVs structure types and their comparison}

There are many structure types of RPVs but the basic structures employed for the transportation of goods are as follows:

- multirotor (Amazon);

- planes (Burito Bomber);

- convertiplanes (Google);

- helicopters (MQ-8 Fire Scout).

Each aircraft has its own characteristics, and its advantages and disadvantages. In Table 2, the different types of aircraft are compared. They have been assessed on a scale from 1 to 4,4 indicates the greatest advantages and 1 the least advantages. The total sum of points shows the best aircraft for cargo transportation. The criteria were applied at the same time; therefore, the results are subjective. 
Table 2. Comparison of RPVs (Heutger, Kückelhaus 2014)

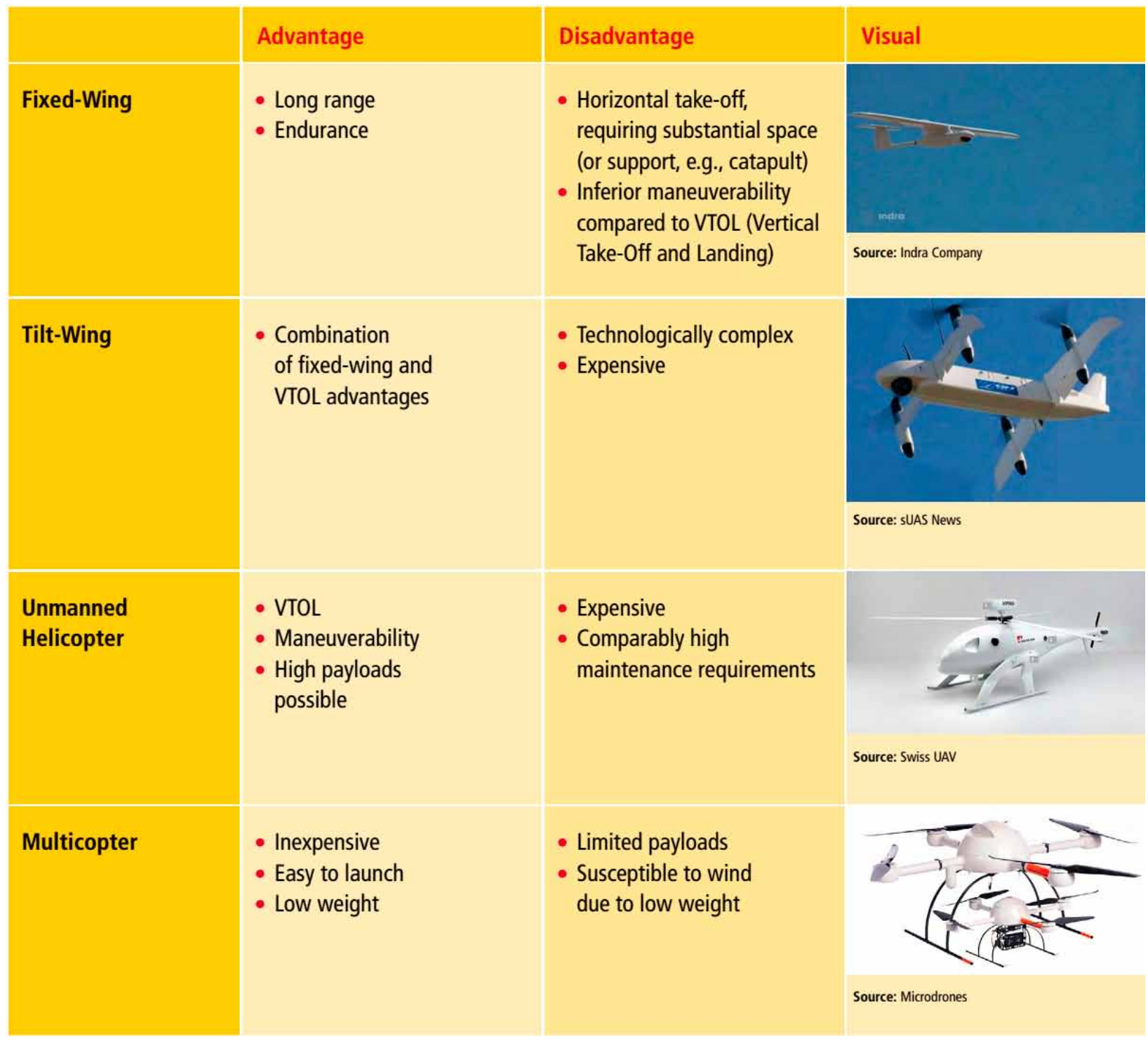

Flight time is directly proportional to the energy source, but with the same amount of energy, a plane performs the longest flight. This is due to the fact that the plane creates the lift force using a fixed wing and the power-plant is used only to create trust. The helicopter and multirotor have to create lift using the rotation of the blades, also, the plot of blades area is usually smaller than that of the airplane's wing.

Flight distance depends on the speed and the time of flight. The plane is the leader according to this criterion. Hybrid aircraft are often equipped with additional rotors to create a vertical lift force, so they have an increased flying resistance.

Take-off is complicated for all aircraft. The plane needs initial speed to create the lift force at the wings. This requires additional equipment (catapults, rocket launchers), or runways. It also complicates the design of the chassis. Helicopter, multirotor or convertiplane aircraft require only a small area for hovering. The convertiplane has the largest disadvantage for hovering due to its automatic control. It requires complex algorithms for the aircraft to take off from an unknown area.

Landing. Landing is one of the most difficult parts of a flight. Multirotors or helicopters can land vertically. An airplane normally uses a runway, but there are other landing options, such as a parachute or a sweep-net. Sometimes vehicles may suffer impact due to a design involving high stall speed.

Production complexity. It is quite simple to manufacture an aircraft and a multirotor. There are no moving parts and they do not need to transmit torque to a distant power-plant. A convertiplane has either moving engines or wings. It complicates the structure and thus manufacturing. The helicopter's tail rotor and moving plate also make the construction very difficult to manufacture. There are also helicopter blades with a changing angle of attack. 
Speed. The airplane is faster than multirotors or helicopters due to aerodynamics. The airplane's speed is limited by engine thrust, unlike a helicopter, whose maximum speed is limited by its mechanical construction. The speed records belong to an airplane but it has stall speed. A helicopter or a multirotor do not have stall speed, they can hover in the air. A convertible has both of these qualities. Both the minimum and maximum speeds are not limited by aerodynamics.

Lifting payload. The magnitude of cargo depends on the lift force created and it is directly proportional to the speed and wing or blade area. Multirotors can raise from 50 to 100 percent of their weight (Jones 2007). However, aircraft wing area and speed are usually higher than those of the other alternatives; so the maximum payload is greater (Faust et al. 2013; Kovanis et al. 2012).

Delivery of the cargo. Aircraft have to fly to a desired point in order to deliver the goods and drop cargo. Aircraft cannot land and take off safely in unknown places, also, a runway is needed. Helicopters or multirotors have the biggest advantage of hovering and releasing cargo in a small area.

\section{Cargo delivery methods and their comparison}

There are lot of different cargo delivery methods; which can be distinguished as illustrated in Figure 7. The categories are based on method that is used for releasing cargo (Headquarters department... 2003).

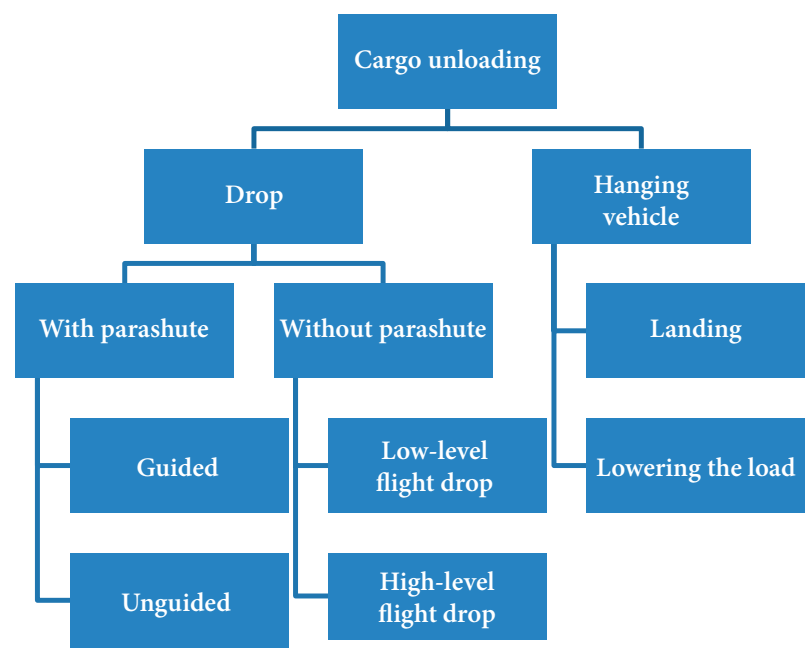

Fig. 7. Cargo delivery methods

Guided parachute. Guided parachutes have some advantages and disadvantages. The landing area is more accurate than that of the unguided parachutes. However, additional measures are needed to control the system and autopilot. The parachute also has unnecessary extra weight that needs to be taken into account when controlling it (Yakimenko, Slegers 2009; Butler et al. 1999).
Unguided parachute is one of the simplest systems. However, precise drop calculations have to be made by the RPV's autopilot. The release time has to be calculated before the drop. It is often difficult to determine weather conditions. During a gusty day, the cargo can be carried really far away from the destination. In a limited space of the area, or in the city, it is difficult to carry out cargo dropping (Butler, Montanez 2007).

Low-level flight drop is a drop without any extra equipment to slow down the acceleration. Therefore, the drop consists of special goods. The advantage is that the load falls to the right place. However, it is dangerous because the aircraft must fly really low.

High-level flight drop. When operating at a highflight level, there is a big chance that the cargo could be damaged. Therefore, it is usually packed in special equipment to cushion the impact. The advantage of that is that the aircraft do not fly dangerously low, but accuracy is a problem.

Hanging and lowering the load. This method can only be used by vehicles which can hover in the air. The cargo is lowered by rope or cable. The biggest advantage is that there is no need of a landing area. It is possible to perform cargo lowering even if there are difficulties or the terrain, location are unfavourable.

Landing and unloading cargo. An aircraft which could land in a limited area and unload the cargo would have the greatest advantage in cargo transportation. Loads are safely lowered to the ground and are then released. Such a method guarantees great accuracy of the location. Nevertheless, the problem is an automatic landing. The aircraft must have additional equipment to monitor the area where it could land and identify those which are dangerous. Therefore, currently the vehicles land with the help of a person. There is no fully automated device which can recognize a new landing area and land and take-off safely.

\section{Mathematical model}

A mathematical model is needed in order to calculate the location of dropping and the time required to reach the ground. The system consists of 3 axes for moving bodies, starting from moving bodies vertically. The first stage includes a simplified model. The mathematical model for motion is provided by Newton's second law, $F=m a$, with a cargo mass $m$ and an acceleration $a . F$ is the sum of gravitational force $F g$ and drag force $F d$ due to air resistance. Therefore, $F g+F d=m a$, where $a=d v / d t$ and $v=$ $d x / d t . F g=-m g$ with $g \approx 9.81 \mathrm{~m} / \mathrm{s}^{2}$. Assuming the force due to friction, $F d$, is proportional to the velocity, we obtain that $F d=-k v$. The force due to air resistance, $k$, will be considered in more detail later in the article. For now, it has one value, $K_{1}$, when the cargo is in free-fall and a second value, $k 2$, when the parachute is fully deployed. If 
the deployment occurs at time $t_{0}$, then we have two cases for the drag Equation (1) (Han et al. 2004).

$$
K=\left\{\begin{array}{rr}
K_{1} & 0 \leq t<t_{0} \\
K_{2} & t \geq t_{0}
\end{array} .\right.
$$

The body forces are weight and the resistance of the elastic force of the parachute. The falling load process is divided into two stages: before the deployment of the parachute and after. During the first stage the parachute resistance will be very low and after inflation it will drastically increase. This change can be described in several ways. One of the ways is simply change the parachute area and drag coefficient from $K_{1}$ to $K_{2}$ (Ke et al. 2006). Also, the parachute area is changing rapidly too (Eq. (2):

$$
S=\left\{\begin{array}{lr}
S_{1} & 0 \leq t<t_{0} \\
S_{2} & t \geq t_{0}
\end{array} .\right.
$$

These equations are applied to each of the bodied: 1 indicates body (Eq. (3)), parachute, 2 (Eq. (4)) indicates the body, tied to the load

$$
\begin{aligned}
& M_{1} \ddot{Y}=-M_{1} g+\frac{1}{2} \rho S \dot{Y}^{2} C_{D 1}-k\left(Y_{1}-Y_{2}\right) ; \\
& M_{2} \ddot{Y}=-M_{2} g+\frac{1}{2} \rho S \dot{Y}^{2} C_{D 2}+k\left(Y_{1}-Y_{2}\right) .
\end{aligned}
$$

Using MATLAB SIMULINK a mathematical model was created. The mathematical model is formed using aggregation constants, integration, and replication blocks, as illustrated by Figure 8 .

Below graphs are presented of the body trajectory velocity in Figure 9. Here the application of the parachute drop trajectories, their speeds and accelerations which can be obtained from specific body characteristics (mass, width, height, speed, elasticity coefficients) is presented. If an autopilot uses this data, the load might fall to the right place.

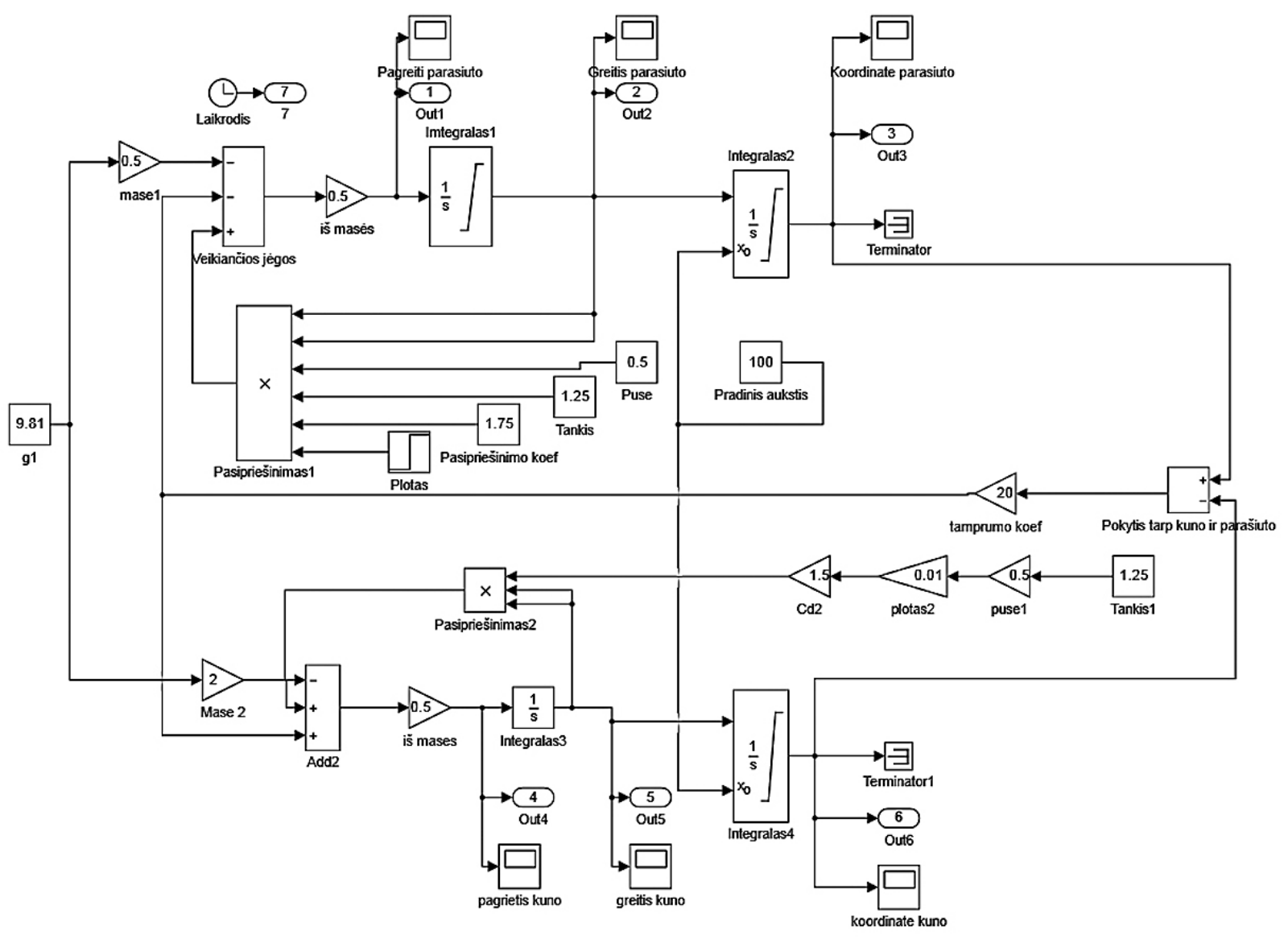

Fig. 8. Mathematical model of cargo dropping 

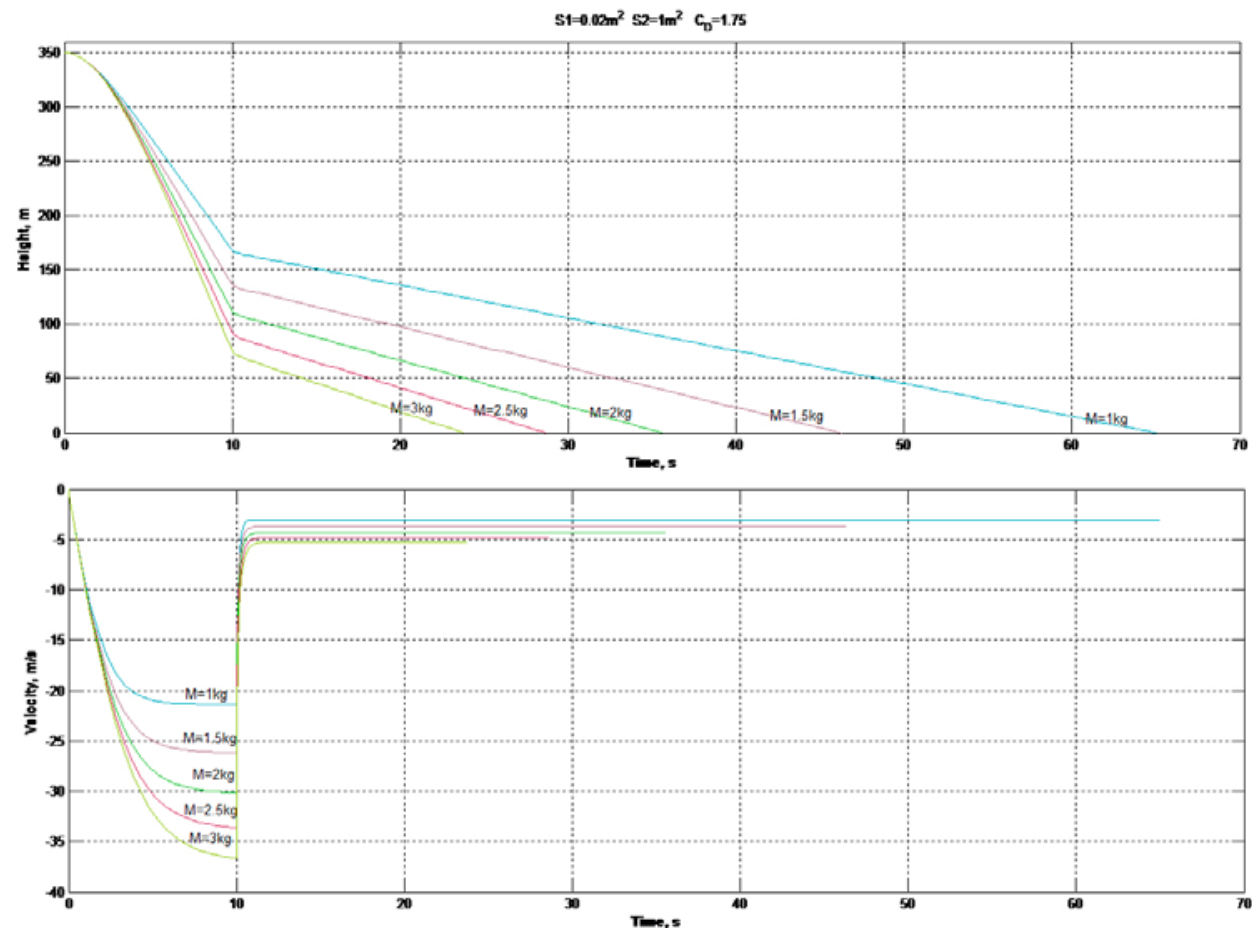

Fig. 9. Changes in parachuted cargo distance and velocity over time

\section{Conclusions}

RPVs are rapidly gaining popularity over the world. They perform various tasks and these tasks are usually combined. Cargo transportation is not a very well developed area, but there are lot of promising projects. The development of mathematical models is the first part of developing cargo systems. This article presents a parachute drop mathematical model, which allows determining the location where the cargo falls. Also, it shows the importance of the weight of the cargo being dropped. The heavier the cargo, the harder the impact that it can reach and the faster it goes down. Additional work will be carried out for the development of the mathematical model which will include horizontal and vertical winds. Also, the experiments will be carried and their results will be compared.

\section{References}

Butler, M. C.; Crowe, M. D.; Systems, B. 1999. The design, development and testing of parachutes using the bat sombrero slider, in Aerodynamic Decelerator Systems Technology Conference, 8-11 June 1999, Toulouse, France.

Butler, M.; Montanez, R. 2007. The selection and qualification of a parachute recovery system for your UAV. SAE Technical Paper 2007-01-3928.

Davis, R. J. 2010, The design and development of a fixed wing UAS for use on RAN patrol boats. LEUT, School of Engineering and Information Technology.
Faust, A.; Palunko, I.; Cruz, P.; Fierro, R.; Tapia, L. 2014. Automated aerial suspended cargo delivery through reinforcement learning, Artifitial Intelligence 1: 1-18. http://dx.doi.org/10.1016/j.artint.2014.11.009

Frew, E. W.; Brown, T. X. 2008. Networking issues for small unmanned aircraft systems, Journal of Intelligent and Robotic Systems 54(1): 21-37. http://dx.doi.org/10.1007/s10846-008-9253-2

Han et al. 2004. Unmanned aerial vehicle (UAV) cargo system, in Systems and Information Engineering Design Symposium, 16 April 2004, Charlottesville, USA.

Headquarters department of the army. 2003. Aerial delivery distribution in the theater of operations. Washington.

Heutger, M.; Kückelhaus, M. 2014. Unmanned aerial vehicles in logistics. Troisdorf: DHL Trend Research.

Jones, E. 2007. New approaches for autonomous logistics aircraft and ground systems, in IET $2^{\text {nd }}$ Autonomous System Conference, 23-23 November 2007, London, UK

Ke, P.; Yang, C.; Yang, X. 2006. Extraction phase simulation of cargo airdrop system, Chinese Journal of Aeronautics 19(4): 315-321. http://dx.doi.org/10.1016/S1000-9361(11)60334-8

Kovanis, A. P.; Skaperdas, V.; Ekaterinaris, J. A. 2012. Design and analysis of a light cargo UAV prototype, Journal of Aerospace Engineering 25(2): 228-237. http://dx.doi. org/10.1061/(ASCE)AS.1943-5525.0000120

Yakimenko, O. A.; Slegers, N. J. 2009. Using direct methods for terminal guidance of autonomous aerial delivery systems, in AIAA Applied Aerodynamics Conference, 23-26 August 2009, Budapest, Hungary. 